\title{
Injury recurrence is lower at the highest professional football level than at national and amateur levels: does sports medicine and sports physiotherapy deliver?
}

Martin Hägglund, Markus Waldén and Jan Ekstrand

\section{Linköping University Post Print}

\section{Tweet}

N.B.: When citing this work, cite the original article.

Original Publication:

Martin Hägglund, Markus Waldén and Jan Ekstrand, Injury recurrence is lower at the highest professional football level than at national and amateur levels: does sports medicine and sports physiotherapy deliver?, 2016, British Journal of Sports Medicine, (50), 12, 751-758.

http://dx.doi.org/10.1136/bjsports-2015-095951

Copyright: BMJ Publishing Group

http://group.bmj.com/

Postprint available at: Linköping University Electronic Press

http://urn.kb.se/resolve?urn=urn:nbn:se:liu:diva-129483 


\title{
Injury recurrence is lower at the highest professional
}

\section{football level than at national and amateur levels: Does}

\section{sports medicine \& sports physiotherapy deliver?}

\author{
Martin Hägglund, , ${ }^{1,2}$ Markus Waldén,,3 Jan Ekstrand ${ }^{2,3}$ \\ ${ }^{1}$ Division of Physiotherapy, Department of Medical and Health Sciences, Linköping University, \\ Linköping, Sweden \\ ${ }^{2}$ Football Research Group, Linköping, Sweden \\ ${ }^{3}$ Division of Community Medicine, Department of Medical and Health Sciences, Linköping \\ University, Linköping, Sweden
}

\section{Corresponding author:}

Martin Hägglund, PhD

Linköping University

Department of Medical and Health Sciences, Division of Physiotherapy

S-581 83, Linköping

Sweden

Tel: + 46733347704

martin.hagglund@liu.se

Key words: epidemiology, football, re-injury, return to play, soccer 
Word count: 3048

Abstract: 258 words 


\begin{abstract}
Background Previous injury is a well-documented risk factor for football injury. The timetrends and patterns of recurrent injuries at different playing levels are not clear.

Aim To compare recurrent injury proportions, incidences and patterns between different football playing levels, and to study time-trends in recurrent injury incidence.

Methods Time-loss injuries were collected from injury surveillance of 43 top-level European professional teams (240 team-seasons), 19 Swedish premier division teams (82 team-seasons) and 10 Swedish amateur teams (10 team-seasons). Recurrent injury was defined as an injury of the same type and at the same site as an index injury within the preceding year, with injury $<2$ months defined as an early recurrence, and $>2$ months as a delayed recurrence. Seasonal trend for recurrent injury incidence, expressed as average annual percentage of change, was analysed using linear regression.
\end{abstract}

Results 13050 injuries were included, 2449 (18.8\%) being recurrent injuries, with 1944 early (14.9\%) and 505 delayed recurrences (3.9\%). Recurrence proportions were highest in the second half of the competitive season for all cohorts. Recurrence proportions differed between playing levels, with $35.1 \%$ in the amateur cohort, $25.0 \%$ in the Swedish elite cohort, and $16.6 \%$ in the European cohort $(\chi 2$ overall effect, $\mathrm{p}<0.001)$. A decreasing trend was observed in recurrent injury incidence in the European cohort; - $2.9 \%$ average annual change over the 14 -year study period ( $95 \%$ CI $-5.4 \%$ to $-0.4 \%, \mathrm{p}=0.026)$. Similarly, a decreasing tendency was also seen in the Swedish premier division.

Conclusions Recurrence proportions showed an inverse relationship with playing level, and recurrent injury incidence has decreased over the last decade. 


\section{INTRODUCTION}

Previous injury is the strongest and best documented risk factor for injury in football, increasing the risk of new injury up to 11 -fold for hamstring injury, ${ }^{1-4} 7$-fold for groin injury, ${ }^{1,4-6}$ and 5-fold for knee ${ }^{1,3}$ and ankle sprains. ${ }^{1,7}$ Thus, lowering recurrence rates may substantially impact the total injury burden.

Injury types with high recurrence proportions in football include hamstring injury (12$45 \%),{ }^{4,8-12}$ groin adductor injury $(14-45 \%),{ }^{4,9,10,13}$ ankle sprain $(9-18 \%)^{10,14,15}$ and lower limb tendinopathies $(20-44 \%){ }^{10,16,17}$

Overall recurrence proportions of 7-22\% have been reported from men's elite/professional football $^{18-24}$ and $14-33 \%$ at amateur level, ${ }^{23,25,26}$ suggesting higher injury recurrence rates with lower playing levels. However, due to study methodological differences and different injury and recurrence definitions it is difficult to compare results between studies.

The objectives of this study were to compare recurrent injury proportions, incidences and patterns between three cohorts of football players of different playing levels, and to study time-trends in recurrent injury incidence in two cohorts of elite/professional players where data have been registered over multiple seasons. 


\section{MATERIAL AND METHODS}

This is a post hoc analysis of prospectively collected data from three cohorts of male football players. The study design adhered to the consensus statement on injury definitions and data collection procedures in football, ${ }^{27}$ and the general methodology has been reported elsewhere. ${ }^{28}$

\section{Study cohorts and inclusion}

The first 'Top-level' cohort included professional football clubs at the highest European level. Forty-three teams from 16 countries participating in the Union of European Football Associations (UEFA) Elite Club Injury Study (UEFA-ECIS) were followed over a varying number of seasons (range 1-14) between 2001 and 2015 (240 team-seasons). ${ }^{19}$ The second 'Elite' cohort includes 19 teams from the Swedish premier division (Allsvenskan) being followed over a varying number of seasons (range 1-9) between 2001 and 2011 (82 teamseasons). ${ }^{3,21,24,29}$ The third 'Amateur' cohort includes 10 teams from the control group of a previous randomized controlled trial followed over one season in 2003 (10 team-seasons). ${ }^{10}$ These teams participated in a regional Swedish division four series (sixth highest division). All players belonging to the first team squads were eligible for inclusion. In total, 6956 player-seasons were included in the Top-level cohort, 2014 in the Elite cohort and 241 in the Amateur cohort. The mean age was 24.0 years (SD 5.3) in the Amateur, 25.2 (4.8) in the Elite and 25.4 (4.6) in the Top-level cohorts, respectively.

\section{Definitions}

Injury was defined as any physical complaint sustained by a player that resulted from a football match or training and led to the player being unable to take a full part in future 
football training or match play. ${ }^{27}$ Players were considered injured until being allowed to fully participate in training and were available for match selection. In the Top-level/Elite cohorts return to play was decided by the club medical staff (doctor or physiotherapist), while in the Amateur cohort this was decided by the coach. Injury severity was based on the number of days lay-off and divided into four categories: slight/minimal (0-3 days), mild (47 days), moderate (8-28 days), and severe (>28 days). An acute injury had a sudden onset and known cause, and an overuse injury had insidious onset and no known trauma.

Recurrent injury was defined as an injury of the same type and at the same site as an index injury within the preceding year. An injury within 2 months after return to full participation from the index injury was defined as an early recurrence and after more than 2 months as a delayed recurrence. In line with the consensus document for football injury surveillance ${ }^{27}$ contusions, lacerations, abrasions, concussions and dental injuries were not eligible for categorization into recurrence or not and were excluded from analyses.

\section{Data collection}

Baseline player data and consent were collected once yearly at the time of player inclusion. During the season, a member of the medical or coaching staff registered individual player exposure in minutes during all club (first team, second team or youth team) and national team training sessions and matches. In the Top-level/Elite cohorts a member of the medical staff diagnosed injuries and filled in an injury form for each injury. ${ }^{28}$ In the Amateur cohort, injured players were examined by a study designated physiotherapist and orthopaedic surgeon, and in some cases one of the authors filled in an injury form based on a structured telephone interview with the player and coach. If an injured player had visited a hospital or 
other clinic for injury assessment, these medical records were also reviewed. Injury and attendance reports were sent to the study group once a month.

\section{Statistical analyses}

Group means and standard deviations (SDs) are presented for age and exposure data. Recurrent injuries are presented as proportions (\% of total no. of injuries) and incidence per $1000 \mathrm{~h}$ with corresponding 95\% confidence interval (CI). Burden is reported as no. and proportion of total injury days lost due to recurrent injury. Group comparisons (within and between cohorts) were made with the $\chi^{2}$ test for categorical variables (recurrent injury proportion), ANOVA for continuous variables (age and exposure data), and a z-test for injury incidences. For the Top-level cohort, a seasonal trend for recurrent injury incidence, expressed as average annual percentage of change, was analysed using linear regression with log-transformed recurrence incidence as the dependent variable. In addition, a 2-year moving average (MA) approach, by summarising two consecutive seasons, was also used as a sensitivity analysis to smooth out any large seasonal variations. All analyses were twosided and the significance level was set at $\mathrm{p}<0.05$. For the between cohort analyses of recurrent injury proportions and incidences a Bonferroni correction was used for pair-wise comparisons, and the significance level set at $\mathrm{p}<0.0167$. 


\section{RESULTS}

There were 15551 injuries registered in total in the three cohorts. Total injury incidences were higher in the Top-level and Elite cohorts than in the Amateur cohort (table 1).

Table 1 Exposure and injury data in three cohorts of male football players

\begin{tabular}{|c|c|c|c|c|}
\hline & Top-level & Elite & Amateur & p Value ${ }^{a}$ \\
\hline \multicolumn{5}{|l|}{ Exposure data } \\
\hline Player-seasons, $\mathrm{n}$ & 6956 & 2014 & 241 & \\
\hline Season exposure, $h$, mean (SD) & $232(94) \dagger$ & $259(98) \dagger$ & $107(42) \dagger+$ & $<0.001$ \\
\hline Season training exposure & $195(79)+$ & $225(84) \dagger$ & $80(32) \dagger+$ & $<0.001$ \\
\hline Season match exposure & $37(25) t$ & $34(18) \dagger$ & $28(13) \dagger+$ & $<0.001$ \\
\hline \multicolumn{5}{|l|}{ Overall injury data } \\
\hline Total injuries, $\mathrm{n}$ & 11581 & 3836 & 134 & \\
\hline Injury incidence, total & $7.2(7.0$ to 7.3$)$ & $7.4(7.1$ to 7.6$)$ & $5.2(4.4$ to 6.1$)+t$ & \\
\hline Injury incidence, training & $3.8(3.7$ to 3.9$) \$$ & $4.9(4.7$ to 5.1$) \dagger$ & $2.7(2.1$ to 3.6$) \$$ & \\
\hline Injury incidence, match play & $25.3(24.7$ to 25.9$) \dagger$ & $23.5(22.4$ to 24.6$) \dagger$ & $12.3(9.9$ to 15.3$) \dagger t$ & \\
\hline Noneligible injuries excluded* & 1824 & 657 & 20 & \\
\hline Injuries included & 9757 & 3179 & 114 & \\
\hline \multicolumn{5}{|l|}{ Recurrent injury data } \\
\hline No recurrence & 8142 & 2385 & 74 & \\
\hline Recurrence, n (\%) & $1615(16.6) \ddagger$ & $794(25.0) \dagger$ & $40(35.1) \dagger$ & $<0.001$ \\
\hline Early recurrence $(<2 \mathrm{mo})$ & $1236(12.7) \ddagger$ & $670(21.1) \dagger$ & $38(33.3) \dagger t$ & $<0.001$ \\
\hline Delayed recurrence $(>2 \mathrm{mo})$ & $379(3.9)$ & $124(3.9)$ & $2(1.8)$ & 0.500 \\
\hline Recurrence incidence, total & $1.00(0.95$ to 1.05$) \ddagger$ & $1.52(1.42$ to 1.63$) \dagger$ & $1.54(1.13$ to 2.11$) \dagger$ & \\
\hline Recurrence incidence, training & $0.58(0.54$ to 0.62$) \$$ & $1.19(1.10$ to 1.30$) \dagger$ & $0.57(0.32$ to 1.03$) \ddagger$ & \\
\hline Recurrence incidence, match play & $3.22(3.01$ to 3.45$)$ & $3.72(3.29$ to 4.21$)$ & $4.36(3.03$ to 6.28$)$ & \\
\hline
\end{tabular}

* Contusions, lacerations, abrasions, concussions and dental injuries were not eligible for categorization into recurrence or not, ${ }^{27}$ and were excluded from analyses $\dagger$ Statistically significant pairwise difference $(\mathrm{p}<0.0167$, Bonferroni correction) compared with Top-level \$ Statistically significant pairwise difference ( $\mathrm{p}<0.0167$, Bonferroni correction) compared with Elite

${ }^{a} \mathrm{P}$ values for overall comparison of column proportions ( $\chi^{2}$ test) or means (ANOVA)

\section{Recurrent injury proportions and incidences}


13050 injuries were eligible for analysis of recurrent injury proportions and incidence (2501 injuries excluded). Of these, 2449 (18.8\%) were recurrent injuries, with 1944 early (14.9\%) and 505 delayed recurrences $(3.9 \%)$. The total and early recurrence proportions differed between cohorts ( $\chi 2$ overall effect, $p<0.001$ ), with the Amateur cohort having the highest and the Top-level cohort the lowest proportions (table 1). The total recurrent injury incidence per $1000 \mathrm{~h}$ was lowest $(\mathrm{p}<0.0167)$ in the Top-level cohort (table 1). The Elite cohort had the highest recurrent injury incidence in training $(\mathrm{p}<0.0167)$, while in match play no significant differences between cohorts were observed. The lowest recurrence proportions were consistently seen during pre-season and the highest in the second half of the competitive season in all cohorts (figure 1).

\section{Recurrent injury patterns}

The recurrent injury patterns in the three cohorts are presented in table 2 . In the Top-level cohort recurrence proportions were comparable between training and match play, while in the Elite cohort the proportion was higher in training $(\mathrm{p}<0.001)$. In the Amateur cohort there was an opposite trend towards a higher recurrence proportion in match play. All cohorts showed a significant difference in recurrence proportion as a function of injury type (table 2). In the comparison between cohorts, the Amateur cohort had consistently high recurrent injury proportions in categories 'muscle rupture/strain/cramps', 'tendon injury/rupture/tendinosis', and 'overuse unspecified', compared with the other cohorts $\left(\chi^{2}\right.$ overall effect, $\mathrm{p}<0.001)$. In all cohorts, the recurrence proportion was higher for overuse injuries than for acute injuries (table 2). 
Table 2 Comparison of injury recurrence patterns between three cohorts of male football players

\begin{tabular}{|c|c|c|c|c|}
\hline & $\begin{array}{l}\text { Top-level } \\
\mathrm{n}(\%)\end{array}$ & $\begin{array}{l}\text { Elite } \\
\mathrm{n}(\%)\end{array}$ & $\begin{array}{l}\text { Amateur } \\
\mathrm{n}(\%)\end{array}$ & p Value $\dagger$ \\
\hline Activity: & $\mathrm{p}=0.086$ & $\mathrm{p}<0.001$ & $\mathrm{p}=0.098$ & \\
\hline Training & $789(17.2)$ & $539(27.4)$ & $11(25.6)$ & $<0.001$ \\
\hline Match play & $826(15.9)$ & $255(21.1)$ & $29(42.8)$ & $<0.001$ \\
\hline Location main $\ddagger$ & $\mathrm{p}<0.001$ & $\mathrm{p}=0.008$ & $\mathrm{p}=0.313$ & \\
\hline Head \& neck & $7(5.6)$ & $2(5.7)$ & 0 & 0.942 \\
\hline Upper limbs & $41(11.5)$ & $14(15.4)$ & 0 & 0.569 \\
\hline Trunk/back & $104(16.8)$ & $63(24.9)$ & $1(12.5)$ & 0.020 \\
\hline Lower limbs & $1463(16.9)$ & $715(25.5)$ & $39(37.9)$ & $<0.001$ \\
\hline Location specific lower limbsł & $\mathrm{p}=0.004$ & $\mathrm{p}<0.001$ & $\mathrm{p}=0.717$ & \\
\hline Hip/groin & $278(17.1)$ & $222(33.9)$ & $5(41.7)$ & $<0.001$ \\
\hline Thigh & $482(17.6)$ & $180(24.2)$ & $5(45.5)$ & $<0.001$ \\
\hline Knee & $289(17.4)$ & $133(22.5)$ & $14(35.0)$ & $<0.001$ \\
\hline Lower leg/Achilles tendon & $189(18.7)$ & $86(26.2)$ & $8(53.3)$ & $<0.001$ \\
\hline Ankle & $193(14.7)$ & $73(19.0)$ & $6(28.6)$ & 0.037 \\
\hline Foot & $32(10.4)$ & $21(21.4)$ & $1(25.0)$ & $<0.001$ \\
\hline Type* & $\mathrm{p}<0.001$ & $\mathrm{p}<0.001$ & $\mathrm{p}=0.031$ & \\
\hline Fracture & $30(7.4)$ & $8(7.6)$ & 0 & 0.958 \\
\hline Other bone injury & $15(18.8)$ & $14(51.9)$ & 0 & 0.001 \\
\hline Dislocation/subluxation & $22(14.2)$ & $11(28.9)$ & 0 & 0.086 \\
\hline Sprain/ligament injury & $220(11.1)$ & $82(13.7)$ & $4(14.3)$ & 0.209 \\
\hline Meniscus/cartilage injury & $82(23.3)$ & $37(28.5)$ & 0 & 0.243 \\
\hline Muscle rupture/strain/cramps & $690(16.4)$ & $276(24.4)$ & $15(48.4)$ & $<0.001$ \\
\hline Tendon injury/rupture/tendinosis & $180(21.8)$ & $107(32.1)$ & $7(43.8)$ & $<0.001$ \\
\hline Nerve injury & $8(18.6)$ & $3(42.9)$ & 0 & 0.151 \\
\hline Synovitis/effusion & $124(32.7)$ & $39(39.8)$ & $3(37.5)$ & 0.412 \\
\hline Overuse unspecified & $176(18.7)$ & $203(31.4)$ & $11(47.8)$ & $<0.001$ \\
\hline Other injury & $68(17.4)$ & $14(21.9)$ & 0 & 0.355 \\
\hline Onset & $\mathrm{p}<0.001$ & $\mathrm{p}<0.001$ & $\mathrm{p}=0.014$ & \\
\hline Overuse & $780(21.1)$ & $503(31.7)$ & $28(45.2)$ & $<0.001$ \\
\hline Acute & $835(13.8)$ & $291(18.3)$ & $12(23.1)$ & $<0.001$ \\
\hline Severity $\ddagger$ & $\mathrm{p}<0.001$ & $\mathrm{p}=0.006$ & $\mathrm{p}=0.090$ & \\
\hline $0-3$ days & $231(15.6)$ & $238(29.0)$ & $3(17.6)$ & $<0.001$ \\
\hline 4-7 days & $310(13.9)$ & $196(23.0)$ & $12(48.0)$ & $<0.001$ \\
\hline $8-28$ days & $703(17.0)$ & $239(22.7)$ & $18(41.9)$ & $<0.001$ \\
\hline$>28$ days & $371(19.3)$ & $121(26.7)$ & $7(24.1)$ & 0.002 \\
\hline
\end{tabular}

Percentages show injury recurrence proportions within each injury category

* Contusions, lacerations, abrasions, concussions and dental injuries were not eligible for categorization into recurrence or not, ${ }^{27}$ and were excluded from analyses

$\dagger \mathrm{P}$ values for overall comparison between column proportions $\left(\chi^{2}\right.$ test)

$\$ \mathrm{P}$ values for comparison within column proportions $\left(\chi^{2}\right.$ test $)$ 
The five most common recurrent injuries and those with the highest burden are presented in table 3. Hamstring injury was the most frequent recurrent injury diagnosis in the Toplevel/Elite cohorts, together with muscle injuries to the adductors and quadriceps. In the Amateur cohort, overuse injury to the patellofemoral joint and patellar tendon were frequent, together with muscle injury to the hamstrings, calf and adductors. Knee anterior cruciate ligament tear and cartilage lesions were represented in the most days lost category due to their high relative severity.

\section{Time-trends in recurrent injury incidence}

In the Top-level cohort, a decreasing trend was observed in recurrent injury incidence with $2.9 \%$ average annual change over the 14 -year period $(95 \% \mathrm{CI}-5.4 \%$ to $-0.4 \%, \mathrm{p}=0.026, \mathrm{MA}$ $-3.8 \%$ per season, figure 2). When analysing the four most common injury type categories (figure 3) a significant decrease was observed in 'muscle rupture/strain/cramps' (-2.5\%) and 'sprain/ligament injury' (-6.1\%).

Due to an inconsistent number of teams participating in the Swedish Elite cohort over the included seasons (1-15 teams per season), no time-trend regression analysis was performed. The full premier division (minimum 12 teams included) was observed in five seasons between 2001 and 2011, and as seen in figure 4 there was a similar decreasing tendency in recurrent injury incidence over time. 
Table 3 Five top recurrent injuries as a function of frequency (n) and burden (injury days lost)

\begin{tabular}{|c|c|c|c|c|c|c|}
\hline & Top-level & & Elite & & Amateur & \\
\hline Frequency* & $n=1615$ & & $n=794$ & & $n=40$ & \\
\hline 1 & Hamstring injury & $22.7 \%$ & Hamstring injury & $15.7 \%$ & Patellofemoral pain & $20.0 \%$ \\
\hline 2 & Adductor-related injury & $11.6 \%$ & Adductor-related injury & $14.2 \%$ & Hamstring injury & $12.5 \%$ \\
\hline 3 & Quadriceps injury & $6.4 \%$ & Achilles tendinopathy & $6.1 \%$ & Calf muscle injury & $12.5 \%$ \\
\hline 4 & Calf muscle injury & $6.1 \%$ & Quadriceps injury & $5.9 \%$ & Adductor-related injury & $10.0 \%$ \\
\hline 5 & Lateral ankle sprain & $6.0 \%$ & Lateral ankle sprain & $5.2 \%$ & Patellar tendinopathy & $7.5 \%$ \\
\hline Sum 1-5 & $n=853$ & $52.8 \%$ & $n=376$ & $47.4 \%$ & $n=25$ & $62.5 \%$ \\
\hline Burdent & 40393 days & & 15991 days & & 737 days & \\
\hline 1 & Hamstring injury & $17.1 \%$ & Adductor-related injury & $11.5 \%$ & Patellar tendinopathy & $21.3 \%$ \\
\hline 2 & Knee cartilage lesion & $8.4 \%$ & Hamstring injury & $10.8 \%$ & Calf muscle injury & $16.6 \%$ \\
\hline 3 & Adductor-related injury & $8.1 \%$ & Knee cartilage lesion & $8.2 \%$ & Lateral ankle sprain & $13.4 \%$ \\
\hline 4 & Achilles tendinopathy & $6.8 \%$ & Knee ACL tear & $7.5 \%$ & Patellofemoral pain & $13.3 \%$ \\
\hline 5 & Quadriceps injury & $6.5 \%$ & Achilles tendinopathy & $4.3 \%$ & Adductor-related injury & $6.6 \%$ \\
\hline Sum 1-5 & 18963 days & $46.9 \%$ & 6758 & $42.3 \%$ & 529 days & $71.8 \%$ \\
\hline
\end{tabular}

ACL anterior cruciate ligament

* Frequency presented as no. and percentage of total no. of recurrent injuries

$\dagger$ Burden presented as no. of days and percentage of total days lost for all recurrent injuries 


\section{DISCUSSION}

Our two main findings were that (i) recurrence proportions showed an inverse relationship with playing level, and (ii) recurrent injury incidence has decreased over the last decade.

\section{Why lower recurrent injury proportions at the highest playing level?}

The Amateur cohort had the highest recurrent injury proportion, with one-third of injuries being recurrences from within a year previously. In the Swedish elite and the European toplevel cohort recurrent injuries accounted for one of four, and one of six injuries, respectively. This meant that, even though the total injury incidence/1000 $\mathrm{h}$ was one-third lower in the amateur clubs, the recurrence incidence was comparable with the Swedish elite teams, and $50 \%$ higher than at the European top-level. This extends a previous report showing a $64 \%$ higher recurrent injury incidence in Dutch amateur versus professional players. ${ }^{23}$ The causes of recurrences were not evaluated in the present study, but some explanations may include:

- Manpower of medical staff: higher playing level is associated with better access to qualified medical and physiotherapy personnel. At the amateur level access to medical staff is scarce, or nonexistent. Teams in the Swedish premier league often have a fulltime physiotherapist and part-time physician, and have access to other consulting health professionals. Further, top-level European clubs often have a large medical and physiotherapy staff working full-time with the team. This staff brings with it several different competences. Thus, having a quick and accurate initial injury assessment, including imaging where necessary, and high-level support during the rehabilitation after injury, is likely a key factor.

- Rehabilitation and return to play: likewise, while injured amateur players may be largely responsible for their own rehabilitation, or with sporadic physiotherapy contact outside 
the club for which they pay themselves, the top-level players have free and daily access to club rehabilitation staff and often train even more during post-injury rehabilitation, up to several hours daily, than when non-injured. Continuous assessment of the player during a graded return to play, as well as maintaining a sufficient level of training-load during the rehabilitation, are probably important factors.

- Larger competitive squads: the average squad sizes were 29 and 24.5 in the Top-level and Elite cohorts, respectively. With a larger competitive player roster the club can afford to have injured players off the pitch with lesser impact on the team's performance, and thus allow sufficient time for rehabilitation. This may compensate for the more intense ('crowded') playing schedule of the elite players.

Other factors such as climate and pitch conditions, playing intensity, seasonal disposition etc. may vary between cohorts and influence the risk of both new and recurrent injury.

\section{Decrease in recurrent injury incidence in professional football}

We have previously shown that the injury incidence was stable between 2001 and 2012 in the UEFA-ECIS cohort. ${ }^{19}$ Similarly, injury incidence in the Swedish premier division have shown no decreasing trend over the last decade., ${ }^{3,21,24,29}$ One study even reported a gradual increase in acute injury incidence between 2002 and 2007 in the Norwegian premier division. ${ }^{18}$ In light of these findings it is encouraging that a $2.9 \%$ yearly decrease in recurrent injury incidence was observed in the European top-level clubs, with a similar decreasing tendency also in the Swedish premier division. In contrast, no decrease in recurrence proportions was found in the aforementioned study of the Norwegian premier division. ${ }^{18}$ 
In the current study, recurrence proportions were highest in the second half of the competitive season for all cohorts. This suggests that towards the end of the league season, or the final stages of domestic and European cups, teams may be tempted to let injured players return to play sooner to play important matches, or to let them play with ongoing minor complaints. Thus, a higher risk tolerance based on the timing of the season may have influenced recurrence rates.

\section{Early recurrences a sign of premature return to play?}

The majority of recurrent injuries in the present study were early recurrences within two months after return to play. In many cases this can be regarded as a sign of premature return. Return-to-play decisions are complex and include assessment of health risk (e.g. medical history, demographics), activity risk (e.g. type of sport, competitive level, ability to protect athlete) and of risk tolerance (e.g. timing of season, pressure from athlete or coaches). ${ }^{30}$

While commonly a battery of clinical criteria, and evaluation of psychological readiness, may be used to guide the return-to-play decision, research evidence supporting their use is largely absent. ${ }^{31}$ We previously showed in an RCT in men's amateur football that teams that used a simple coach-led 10-step return to play protocol had a $66 \%$ lower recurrence risk compared with control teams. ${ }^{10}$ This recurrent injury preventive effect was most pronounced within the first four weeks of return to play, showing that, at amateur level, many early recurrences can be avoided.

\section{Avoiding muscle and tendon recurrences - a key to reduce the injury burden}


There are high recurrence rates among lower extremity muscle injuries ${ }^{1-6,8-13,21}$ and tendon injuries ${ }^{10,16,17}$ in football, and that was confirmed in our study. Together, such injuries comprised about half of all recurrent injuries, with hamstring injury being the most common. We have previously reported that hamstring recurrences showed an increasing tendency in this UEFA-ECIS cohort, with an annual year on year rise of $3 \%$ and a total 13-year rise of $42 \% .{ }^{32}$ Thus actions to prevent hamstring injury recurrences are urgent across all playing levels.

The Nordic hamstring exercise reduces the incidence of index, and especially recurrent, hamstring injuries in football players. ${ }^{33} \mathrm{~A}$ recent systematic review concluded that specific rehabilitation programmes after hamstring injury (lengthening exercises, agility and trunk stabilisation exercises) currently showed no or limited evidence for recurrent injury risk reduction. ${ }^{34}$ The high hamstring recurrence proportions suggest presence of persistent risk factors after return to play, and neuromuscular inhibition after injury (with eccentric weakness, selective muscle atrophy of the long head of biceps femoris, and alterations in the angle of peak knee flexor torque) was recently proposed as a key factor. ${ }^{35}$ A prospective follow-up of 61 patients (a majority being competitive football players) with hamstring injury identified four risk factors for recurrent injury; more previous hamstring injuries, active knee extension deficit, isometric knee flexion force deficit, and presence of localized discomfort on palpation just after return to play. ${ }^{36}$

For lower extremity tendon injuries, a previous report from the UEFA-ECIS cohort showed higher recurrence risk for Achilles tendon injuries with return to play after short ( $\leq 10$ days) recovery $(31 \%)$ compared with longer (>10 days) recovery periods $(13 \%),{ }^{16}$ probably reflecting the recursive nature of tendinopathies and premature return to high-load training and match play. Since players may have no or only minor symptoms from the tendon during sports participation they may be tempted to return at an early stage, and evaluation of 
symptoms (e.g. pain, stiffness, swelling) the day after training may help to guide the increase in training intensity and volume. ${ }^{37}$ Many overuse injuries, including tendon injuries, may go unreported in traditional injury surveillance, ${ }^{38}$ and also to club medical staffs, since they do not cause absence from sports. Hence, a systematic approach to capture overuse injuries, including those not leading to time-loss, could help further in the management and return-toplay decision for these common injuries.

To date, evidence for prevention of lower extremity muscle and tendon recurrences is scarce. So, despite the encouraging finding that overall muscle recurrent injury incidences showed a decreasing trend, recurrences are still common and further study on risk factors and interventions to reduce recurrent injury risk is warranted. This should also include the influence of external factors. For instance, match congestion has been associated with increase in muscle injury rates ${ }^{39}$ and player workload during rehabilitation and upon return to play after injury is likely to also influence injury recurrence risk. ${ }^{40}$

\section{Methodological considerations}

The main strength of this study is the large long-term prospective dataset of professional football, using the same data collection procedures and definitions across seasons and cohorts, enabling time-trend analyses of recurrent injury incidences and comparisons between cohorts. There are also some limitations with the current study. The dataset from amateur football was small, with one season only, which gave no possibility for time-trend observations of injury risk. The small dataset also limits the generalization of our findings to amateur football in general. Moreover, data from the Amateur cohort were collected in 2003 only, with the Top-level and Elite cohorts followed up until 2015 and 2011, respectively. 
Since the recurrent injury incidence showed a decreasing trend over time, this temporal component should be kept in mind in the comparisons between cohorts. To address this we made a sensitivity analysis comparing recurrence proportions including only seasons 2002 to 2004 in the Top-level and Elite cohorts. This gave similar results with $35.1 \%$ in the Amateur, $27.6 \%$ in the Elite and $16.4 \%$ in the Top-level cohorts, respectively ( $\chi 2$ overall effect, $\mathrm{p}<0.001)$. Another consideration is that even though the methodology and definitions were very similar in all cohorts, the reporting standards of injuries and recurrences may vary between teams, countries and playing levels. The lesser training and match exposures in the Amateur cohort, and delayed access to medical check-up and diagnosis, means that the risk of missing eligible injuries is probably higher, and the accuracy of injury and recurrence diagnosis is probably lower. The teams included in the two professional cohorts varied to some extent over seasons, and this could influence both the true injury rates as well as reporting thresholds and procedures of (recurrent) injury recording, with new medical staffs entering the study. Finally, we have no information about the actual return to play practices used in the different clubs, and such procedures may also have varied between seasons. Hence the causes of injury recurrences cannot be deducted from the current study.

\section{What are the new findings?}

- An inverse relationship was found between the playing level and recurrent injury proportions in men's football (i.e. players at top-level clubs had a lower injury recurrence rate). We speculate that better staffed medical and physiotherapy teams, high-quality rehabilitation and support in the return to play, and larger competitive squads allowing for sufficient rehabilitation time, contribute to lower recurrence rates among players at top-level clubs. 
- Recurrent injury incidence is decreasing in European top-level clubs and in the Swedish premier league.

- Recurrence proportions were higher in the second half of the competitive season compared with the first half of the season and pre-season. This may be due to higher risk tolerance in return-to-play decisions towards the final stages of league play and cups.

\section{How might the study impact clinical practice?}

- Professional football clubs could reduce their overall injury burden further by avoiding recurrent injuries, especially lower extremity muscle and tendon injuries which accounted for half of all reported recurrences, and with hamstring injury being the most frequent diagnosis.

- The high rate of early recurrences within two months suggests that avoiding premature return to play is a crucial component to decrease the overall recurrent injury incidence.

- Strict adherence to rehabilitation protocols and graded return to play throughout the entire season, and ensuring respect for such protocols from all stakeholders within the club from the player, medical staff, fitness staff, and coaches to the members of the board, may help reduce the injury burden. 


\section{ACKNOWLEDGEMENTS}

The authors wish to thank all the participating clubs including coaches, players and medical staffs. Biostatistician Henrik Magnusson is acknowledged for assistance with the statistical analyses.

\section{CONTRIBUTORSHIP STATEMENT}

$\mathrm{MH}$ was responsible for the conception and design of the study. All authors were involved in data collection over the study periods. $\mathrm{MH}$ conducted the analyses together with the biostatistician (HM) and they were planned and checked with MW and JE. All authors contributed to interpretation of the findings and had full access to all data. $\mathrm{MH}$ wrote the first draft of the paper, which was critically revised by MW and JE. The final manuscript was approved by all authors. MH is the study guarantor.

\section{FUNDING}

The Football Research Group has been established in Linköping, Sweden, in collaboration with Linköping University and through grants from the Union of European Football Associations, the Swedish Football Association, the Football Association Premier League Limited, and the Swedish National Centre for Research in Sports.

\section{ETHICS APPROVAL}

The study design was approved by the UEFA Medical Committee and the UEFA Football Development Division for the UEFA Elite Club Injury Study, and by the Regional Ethics committee of Linköping for the Swedish premier division and amateur cohorts (\#02-316, \#73/04, \#M240-09).

\section{PROVENANCE AND PEER REVIEW}


Not commissioned; externally reviewed. 


\section{REFERENCES}

1. Árnason Á, Sigurdsson SB, Gudmundsson A, et al. Risk factors for injuries in football. Am J Sports Med 2004;32:5S-16S.

2. Engebretsen AH, Myklebust G, Holme I, et al. Intrinsic risk factors for hamstring injuries among male soccer players: a prospective cohort study. Am J Sports Med 2010;38:1147-53.

3. Hägglund M, Waldén M, Ekstrand J. Previous injury as a risk factor for injury in elite football - a prospective study over two consecutive seasons. Br J Sports Med 2006;40:767-72.

4. Hägglund M, Waldén M, Ekstrand J. Risk factors for lower extremity muscle injury in professional soccer: the UEFA injury study. Am J Sports Med 2013;41:327-35.

5. Engebretsen AH, Myklebust G, Holme I, et al. Intrinsic risk factors for groin injuries among male soccer players: a prospective cohort study. Am J Sports Med 2010;38:2051-7.

6. Hölmich $\mathrm{P}$, Thorborg $\mathrm{K}$, Dehlendorff $\mathrm{C}$, et al. Incidence and clinical presentation of groin injuries in sub-elite male soccer. Br J Sports Med 2014;48:1245-50.

7. Engebretsen AH, Myklebust G, Holme I, et al. Intrinsic risk factors for acute ankle injuries among male soccer players: a prospective cohort study. Scand J Med Sci Sports 2010;20:403-10.

8. Cross KM, Gurka KK, Saliba S, et al. Comparison of hamstring strain injury rates between male and female intercollegiate soccer athletes. Am J Sports Med 2013;41:742-8.

9. Ekstrand J, Hägglund M, Waldén M. Epidemiology of muscle injuries in professional football (soccer). Am J Sports Med 2011;39:1226-32.

10. Hägglund M, Waldén M, Ekstrand J. Lower reinjury rate with a coachcontrolled rehabilitation program in amateur male soccer: a randomized controlled trial. Am J Sports Med 2007;35-9:1433-42.

11. Petersen J, Thorborg K, Nielsen MB, et al. Acute hamstring injuries in Danish elite football: A 12-month prospective registration study among 374 players. Scand J Med Sci Sports 2010;20:588-92.

12. Woods C, Hawkins RD, Maltby S, et al. The Football Association Medical Research Programme: an audit of injuries in professional football--analysis of hamstring injuries. Br J Sports Med 2004;38:36-41.

13. Werner J, Hägglund M, Waldén M, et al. UEFA injury study: a prospective study of hip and groin injuries in professional football over seven consecutive seasons. $\mathrm{Br} \mathrm{J}$ Sports Med 2009;43:1036-40.

14. Waldén M, Hägglund M, Ekstrand J. Time-trends and circumstances surrounding ankle injuries in men's professional football: an 11-year follow-up of the UEFA Champions League injury study. Br J Sports Med 2013;47:748-53.

15. Woods C, Hawkins R, Hulse M, et al. The Football Association Medical Research Programme: an audit of injuries in professional football: an analysis of ankle sprains. Br J Sports Med 2003;37:233-8.

16. Gajhede-Knudsen M, Ekstrand J, Magnusson H, et al. Recurrence of Achilles tendon injuries in elite male football players is more common after early return 
to play: an 11-year follow-up of the UEFA Champions League injury study. $\mathrm{Br}$ J Sports Med 2013;47:763-8.

17. Hägglund M, Zwerver J, Ekstrand J. Epidemiology of patellar tendinopathy in elite male soccer players. Am J Sports Med 2011;39:1906-11.

18. Bjørneboe J, Bahr R, Andersen TE. Gradual increase in the risk of match injury in Norwegian male professional football: a 6-year prospective study. Scand $J$ Med Sci Sports 2014;24:189-96.

19. Ekstrand J, Hägglund M, Kristenson K, et al. Fewer ligament injuries but no preventive effect on muscle injuries and severe injuries: an 11-year follow-up of the UEFA Champions League injury study. Br J Sports Med 2013;47:732-7.

20. Hawkins RD, Hulse MA, Wilkinson C, et al. The association football medical research programme: an audit of injuries in professional football. Br J Sports Med 2001;35:437.

21. Hägglund M, Waldén M, Ekstrand J. Injuries among male and female elite football players. Scand J Med Sci Sports 2009;19:819-27.

22. Stubbe JH, van Beijsterveldt AM, van der Knaap S, et al. Injuries in professional male soccer players in the Netherlands: a prospective cohort study. J Athl Train 2015;50:211-6.

23. van Beijsterveldt AM, Stubbe JH, Schmikli SL, et al. Differences in injury risk and characteristics between Dutch amateur and professional soccer players. $J$ Sci Med Sport 2015;18:145-9.

24. Waldén M, Hägglund M, Ekstrand J. Injuries in Swedish elite football - a prospective study on injury definitions, risk for injury and injury pattern during 2001. Scand J Med Sci Sports 2005;15:118-25.

25. Ekstrand J, Gillquist J, Liljedahl SO. Prevention of soccer injuries: supervision by doctor and physiotherapist. Am J Sports Med 1983;11:116-20.

26. Schmikli SL, de Vries WR, Inklaar H, et al. Injury prevention target groups in soccer: injury characteristics and incidence rates in male junior and senior players. J Sci Med Sport 2011;14:199-203.

27. Fuller CW, Ekstrand J, Junge A, et al. Consensus statement on injury definitions and data collection procedures in studies of football (soccer) injuries. Br J Sports Med 2006;40:193-201.

28. Hägglund M, Waldén M, Bahr R, et al. Methods for epidemiological study of injuries to professional football players: developing the UEFA model. Br J Sports Med 2005;39:340-6.

29. Kristenson K, Bjørneboe J, Waldén M, et al. The Nordic Football Injury Audit: higher injury rates for professional football clubs with third-generation artificial turf at their home venue. Br J Sports Med 2013;47:775-81.

30. Shrier I. Strategic Assessment of Risk and Risk Tolerance (StARRT) framework for return-to-play decision-making. Br J Sports Med 2015;49:13115.

31. Ardern CL, Bizzini M, Bahr R. It is time for consensus on return to play after injury: five key questions. Br J Sports Med Published Online First: 20 November 2015. doi:10.1136/bjsports-2015-095475.

32. Ekstrand J, Waldén M, Hägglund M. Hamstring injuries have increased by $4 \%$ annually in men's professional football, since 2001: a 13-year longitudinal 
analysis of the UEFA Elite Club Injury Study. Br J Sports Med Published Online First: 8 January 2016. doi:10.1136/bjsports-2015-095259.

33. Petersen J, Thorborg K, Nielsen MB, et al. Preventive effect of eccentric training on acute hamstring injuries in men's soccer: a cluster-randomized controlled trial. Am J Sports Med 2011;39:2296-303.

34. Pas HIMFL, Reurink G, Tol JL, et al. Efficacy of rehabilitation (lengthening) exercises, platelet-rich plasma injections, and other conservative interventions in acute hamstring injuries: an updated systematic review and meta-analysis. $\mathrm{Br}$ J Sports Med 2015;49:1197-1205.

35. Opar DA, Williams MD, Shield AJ. Hamstring strain injuries: factors that lead to injury and re-injury. Sports Med 2012;42:209-26.

36. De Vos R-J, Reurink G, Goudswaard G-J, et al. Clinical findings just after return to play predict hamstring re-injury, but baseline MRI findings do not. $\mathrm{Br}$ J Sports Med 2014;48:1377-84.

37. Silbernagel KG, Crossley KM. A proposed return-to-sport program for patients with midportion Achilles tendinopathy: rationale and implementation. J Orthop Sports Phys Ther 2015;45:876-86.

38. Clarsen B, Myklebust G, Bahr R. Development and validation of a new method for the registration of overuse injuries in sports injury epidemiology: the Oslo Sports Trauma Research Centre (OSTRC) Overuse Injury Questionnaire. Br J Sports Med 2013;47:495-502.

39. Bengtsson H, Ekstrand J, Hägglund M. Muscle injury rates in professional football increase with match congestion - an 11-year follow up of the UEFA Champions League injury study. Br J Sports Med 2013;47:743-7.

40. Blanch P, Gabbett TJ. Has the athlete trained enough to return to play safely? The acute:chronic workload ratio permits clinicians to quantify a player's risk of subsequent injury. Br J Sports Med Published Online First: 23 December 2015. doi:10.1136/bjsports-2015-095445. 


\section{TABLE AND FIGURE LEGENDS}

Table 1 Exposure and injury data in three cohorts of male football players

Table 2 Comparison of injury recurrence patterns between three cohorts of male football players

Table 3 Five top recurrent injuries as a function of frequency (n) and burden (injury days lost)

Figure 1 Recurrent injury proportion as a function of part of season.

Top-level cohort has pre-season June-July, first half competitive season August-December, and second half competitive season January-May; the Elite and Amateur cohorts have pre-season January-March, first half competitive season April-July, and second half competitive season August-October/November

Figure 2 Time-trend in recurrent injury incidence (re-injuries/1000 h) in the UEFA Elite Club Injury Study 'Top-level cohort' over 14 seasons

There was a statistically significant decreasing trend with $-2.9 \%$ annual change (95\% CI $-5.4 \%$ to $0.4 \%, \mathrm{p}=0.026$; moving average $-3.8 \%$ per season).

Figure 3 Time-trend in recurrent injury incidence (injuries/1000 h) in the UEFA Elite Club Injury Study 'Top-level cohort' over 14 seasons as a function of injury type The graph shows 2-year moving average injury incidences. Regression analysis showed a significant decreasing trend for 'muscle rupture/strain/cramps' (-2.5\% average change per season, 95\% CI $-3.7 \%$ to $-1.26 \%, \mathrm{p}<0.001)$ and 'sprain/ligament injury' $(-6.1 \%, 95 \% \mathrm{CI}-10.8 \%$ to $-1.1 \%$, $\mathrm{p}=0.021)$, while no significant trends were observed for 'tendon injury/rupture/tendinosis' $(-5.0 \%$, $95 \% \mathrm{CI}-11.4 \%$ to $1.8 \%, \mathrm{p}=0.133)$ or 'overuse unspecified' $(-0.7 \%, 95 \% \mathrm{CI}-7.9 \%$ to $7.0 \%$, $\mathrm{p}=0.835$ ). Injuries in category 'overuse unspecified' included e.g. unspecified groin pain, low back pain, patellofemoral pain, and medial tibial pain.

Figure 4 Recurrent injury incidence (injuries/1000 h) in the Swedish men's premier division 'Elite cohort'

Only full seasons ( $\mathrm{n}=5$, minimum 12 teams included) are presented, showing a decreasing tendency for recurrent injuries overall, as well as for injury type categories 'muscle rupture/strain/cramps' and 'overuse unspecified'. Injuries in category 'overuse unspecified' included e.g. unspecified groin pain, low back pain, patellofemoral pain, and medial tibial pain. 


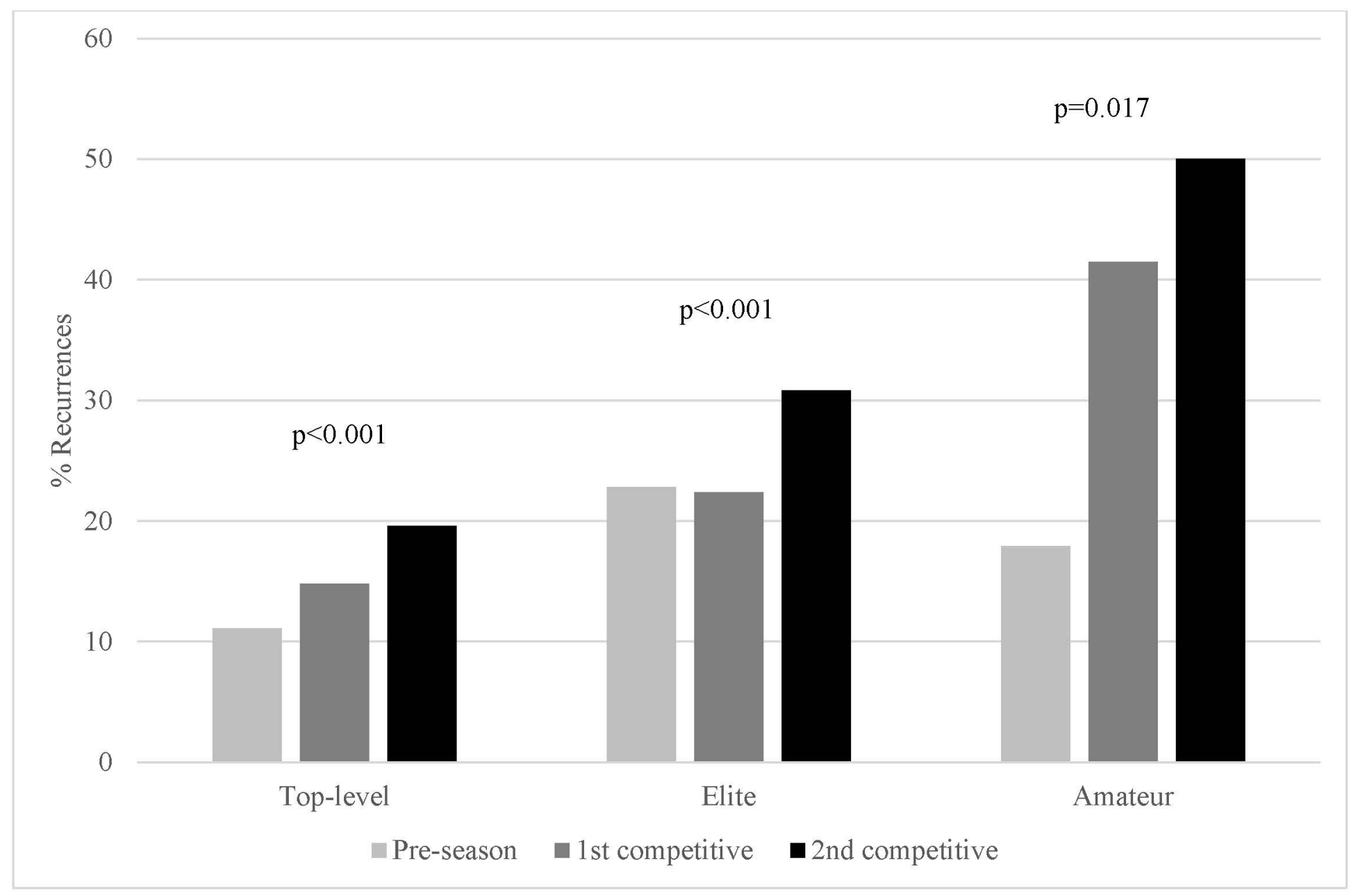




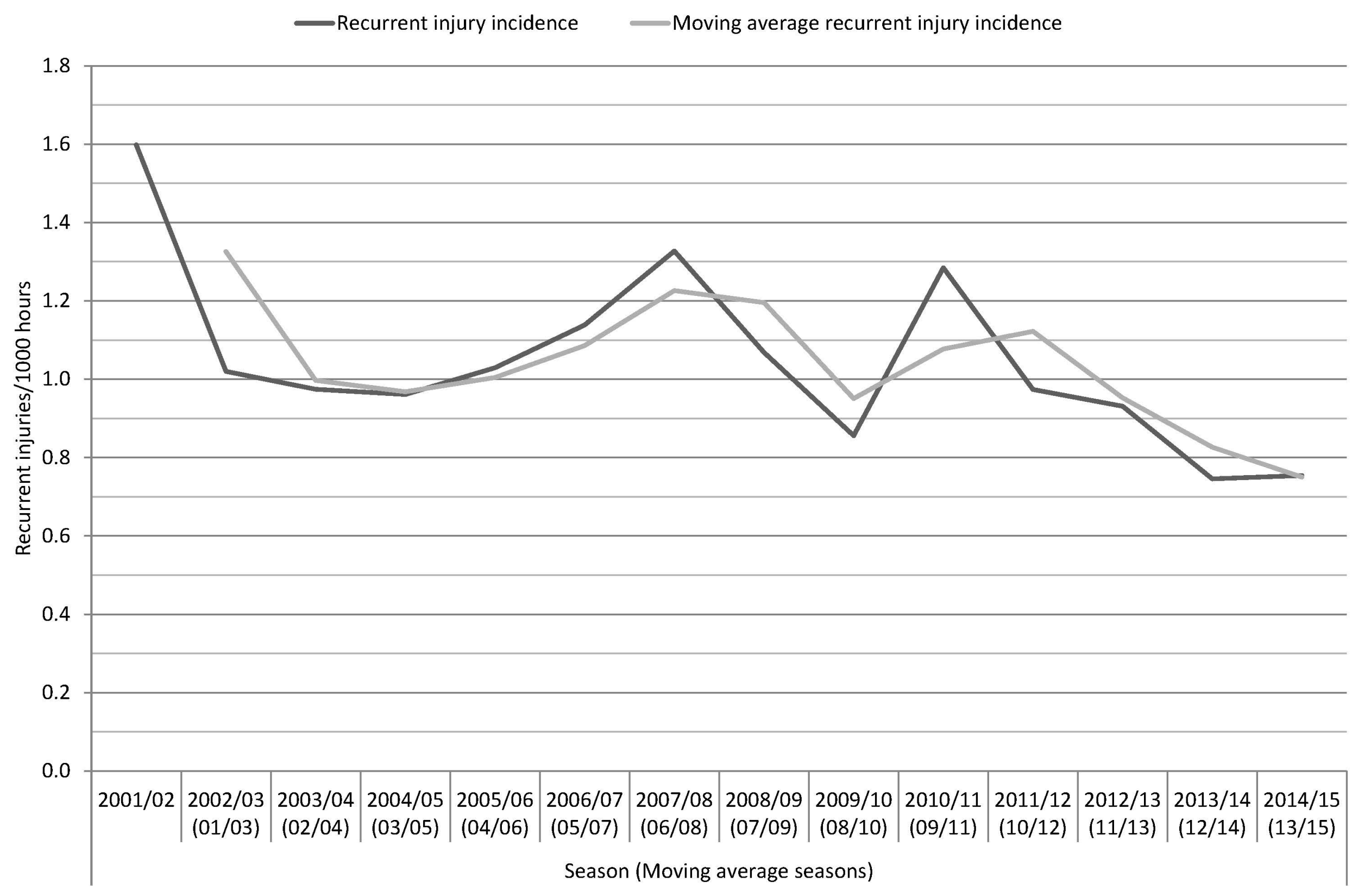




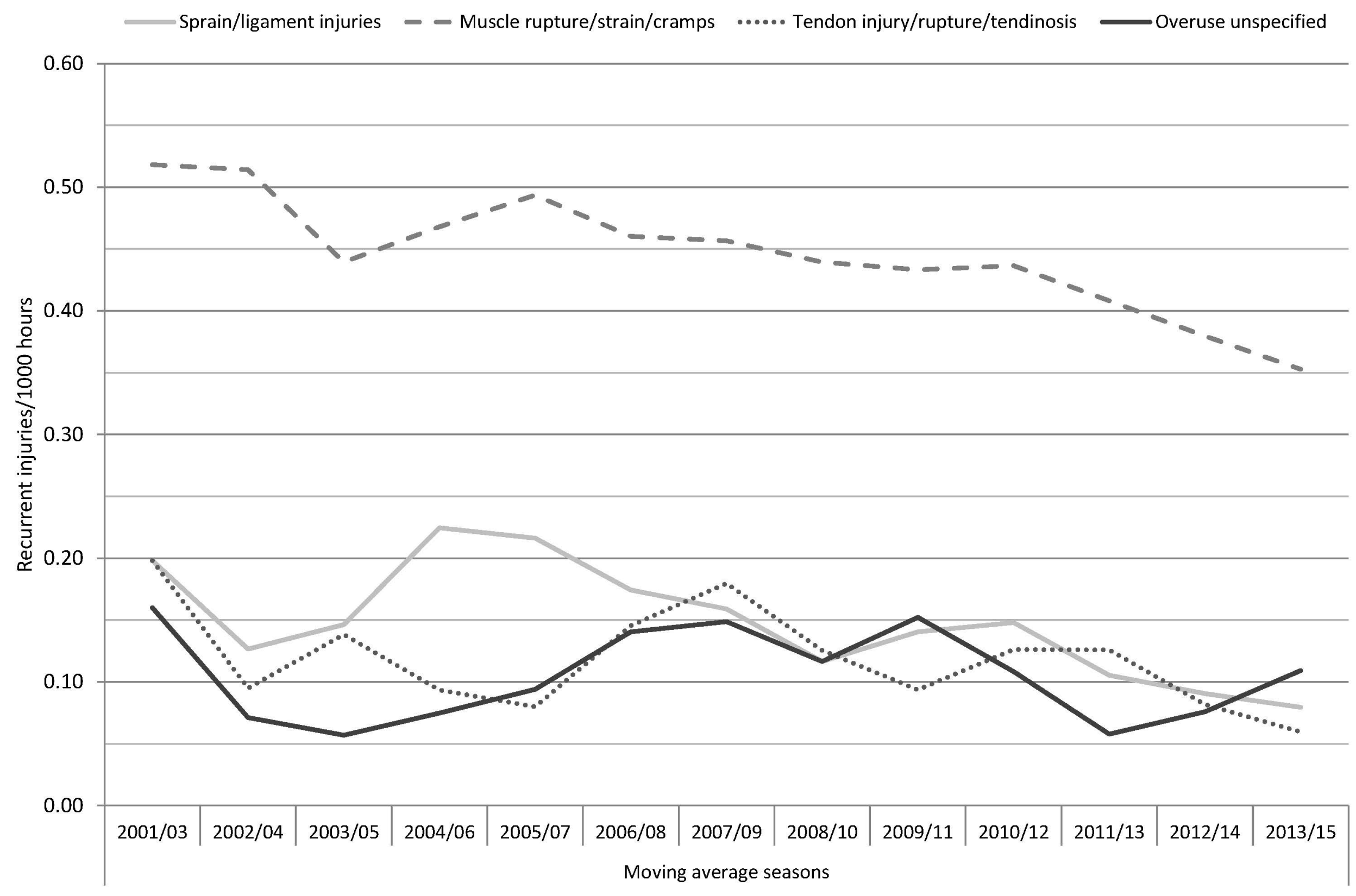




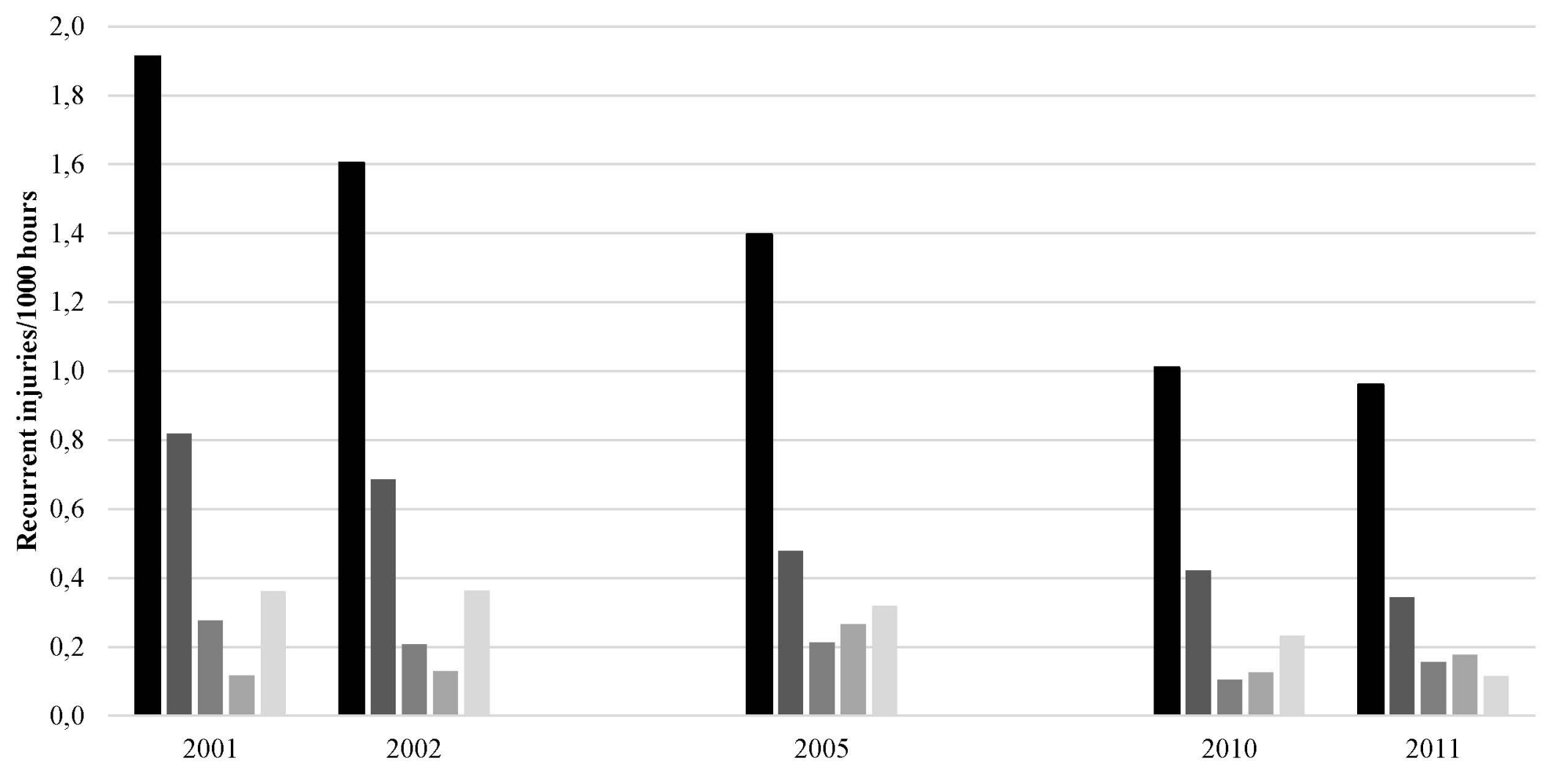

- Total recurrences $\square$ Muscle rupture/strain/cramp $\backsim$ Tendon injury/rupture/tendinosis $\square$ Sprain/ligament injury $\square$ Overuse unspecified 